\section{Pesquisas recentes sobre material lítico na Arqueologia Brasileira}

\section{Por João Aires da Fonseca}

Mestre em Arqueologia pela Universidade de São Paulo. Bolsista do Programa de Capacitação Institucional do Museu Paraense Emílio Goeldi/MCT. Curador do Museu do Marajó (airesarch@gmail.com)

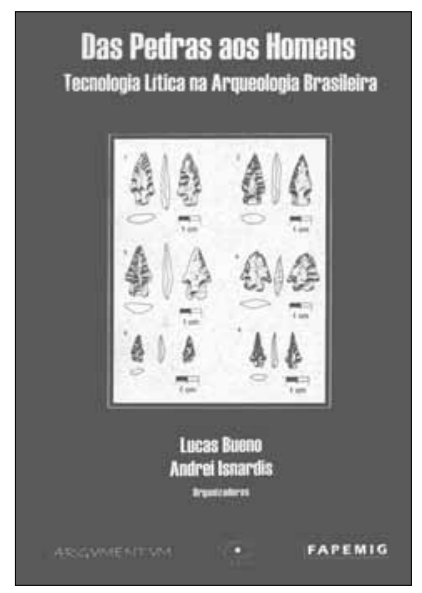

BUENO, Lucas; ISNARDIS, Andrei (Orgs.). Das pedras aos homens: tecnologia lítica na Arqueologia Brasileira. Belo Horizonte: Argvmentvm, 2007. 270 p.: il. ISBN 978-8598885-24-7.

O livro "Das pedras aos homens" surgiu a partir das ideias discutidas no seminário "Tecnologia Lítica no Brasil. Fundamentos teóricos, problemas e perspectivas de pesquisa". Organizado por Lucas Bueno e Andrei Isnardis, o livro tem como proposta reunir pesquisadores de diferentes formações científicas dentro da arqueologia, disponibilizando aos leitores um panorama não somente interessante como também essencial para que a arqueologia brasileira se torne cada vez mais sólida em conceitos e metodologias de pesquisa. Não há dúvida de que somente com esta diversidade de pesquisadores foi possível alcançar a proposta de se escrever um panorama de problemas e perspectivas sobre o contexto do material lítico em sítios arqueológicos brasileiros.

O que o livro apresenta ao longo de seus onze capítulos são as novas abordagens para o estudo deste tipo de material, não permanecendo somente nos estudos das 'pedras' (rochas) em si, mas indo além, criando contextos e quadros hipotéticos que permitem ir "das pedras aos homens". Esta coletânea de artigos passa a ser uma referência atual sobre o estudo de tecnologia lítica na arqueologia brasileira, disponibilizando referências bibliográficas úteis sobre os temas abordados, o que permite aos leitores, em especial estudantes de arqueologia, um maior aprofundamento sobre os temas descritos.

Como exemplo, quais são as referências existentes sobre arqueologia experimental no Brasil? Como esta parte da arqueologia vem se desenvolvendo atualmente? É neste ponto que "Experimentação na Arqueologia Brasileira: entre gestos e funções", de André Prous, e "Recent advances in stone-tool reduction analysis: A review for Brazilian archaeologists", de Michael Shott, trazem à tona uma revisão do uso da experimentação.

André Prous introduz a importância da etnoarqueologia e do esforço próprio que o arqueólogo precisa ter ao reproduzir e utilizar o que poderiam ser as réplicas de instrumentos arqueológicos. Desta forma, o pesquisador aborda o material lítico a partir da experimentação, adquirindo mais dados para suas interpretações dos vestígios coletados e de seus prováveis contextos. É neste sentido também que a argumentação de Michael Shott incide sobre os diversos processos de redução que um artefato lítico pode ter passado, seja por meio do uso intenso ou de retoques para reavivar gumes, por exemplo.

As interpretações sobre o contexto arqueológico assumem um papel muito importante neste livro. Tal importância é justamente por ser esta a principal meta das pesquisas arqueológicas recentes. Para Andrei Isnardis, autor do capítulo "Notas sobre a solidão das indústrias líticas", a distribuição espacial de diversos vestígios é essencial para retirar as indústrias líticas do que ele considera como "solidão". Trata-se de uma crítica às pesquisas que lidam com os materiais analisados de maneira isolada, deixando de lado a interpretação do restante do material coletado, criando, assim, interpretações parciais do contexto do sítio.

Tal problema de interpretações parciais pode advir das divisões por grandes classes de vestígios. Para Isnardis, alguns pesquisadores acabam sendo caracterizados como 'arqueólogos do lítico', 'arqueólogos da cerâmica' ou

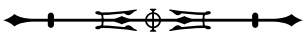


'arqueólogos da arte rupestre'. A especialização dos pesquisadores acaba por causar este isolamento do material analisado, contudo, como o principal objetivo das pesquisas são as sociedades humanas, existe a necessidade de estudos que usem os vários artefatos dentro de um conjunto para que se chegue às possíveis interpretações de contextos sociais mais complexos, e não apenas de uma parte especializada.

Como exemplos desta necessidade de interpretar diversos dados, buscando uma visão dinâmica sobre a préhistória brasileira, na tentativa de articular vestígios, sítios, regiões e macrorregiões, pode-se citar os capítulos sobre o Brasil Central, "Organização tecnológica e Teoria do Design: entre estratégias e características de performance", de Lucas Bueno, e "Metodologia de análise para as indústrias líticas do Pleistoceno no Brasil Central", de Águeda Vilhena-Vialou.

Outra vertente clara no livro, tomada por todos os seus autores, é a inviabilidade, ou ineficácia, em se produzir estudos arqueológicos que contemplem estudos tipológicos baseados unicamente em instrumentos acabados. Como abordado por Jacqueline Rodet em "Uma terminologia para a indústria lítica brasileira", e por Paulo Jobim em "Possibilidades de abordagens em indústrias expedientes", existe uma tendência, iniciada na década de 1980, para a inserção nos estudos de contexto e de tecnologia dos conceitos de cadeia operatória, gesto, teoria do design e experimentação, em vez de estudos meramente tipológicos de peças já acabadas, enfatizando a necessidade de homogeneização da terminologia utilizada pelos pesquisadores, buscando-se sistematizar as nomenclaturas para a análise da tecnologia lítica.

Mais exemplos advém de Pedro Schmitz em "O estudo das indústrias líticas no PRONAPA, seus seguidores e imitadores"; de Adriana Schmidt em "Da tipologia à tecnologia: reflexões sobre a variabilidade das indústrias líticas da Tradição Umbu"; e de Sirlei Hoeltz em "Contexto e tecnologia: parâmetros para uma interpretação das indústrias líticas do Sul do Brasil".

O capítulo de Pedro Schmitz caracteriza o papel da ciência arqueológica: cada época possui um contexto e limitações de pesquisa, e cada época sucessora irá acumular conhecimentos de épocas anteriores, reformulando-os e aplicando novos. A principal diferença entre o Programa Nacional de Pesquisas Arqueológicas (PRONAPA) da década de 1970 e as pesquisas recentes, como a desenvolvida na Floresta Atlântica, é o maior dinamismo das pesquisas que, com o quadro teórico atual, possibilitaram chegar a conclusões regionais e mais amplas sobre a ocupação humana na região Sul do Brasil. Nesta mesma linha, Adriana Schmidt e Sirlei Hoeltz enfatizam a importância dos estudos que enfocam o caráter regional e que respeitam a contextualização espacial dos sítios, em suas características internas e externas, associadas a propostas metodológicas que compreendam a variabilidade artefatual como resultado de escolhas tecnológicas, na busca por identidades sociais no registro arqueológico.

Por fim, temos o divertido experimento literário escrito por Klaus Hilbert, "Indústrias líticas como vetores de organização social ou: Um ensaio sobre pedras e pessoas". Hilbert preferiu intuir, explicando por meio de crônicas e múltiplas narrativas, "as pedras arqueológicas e as pedras lúdicas da infância e adolescência", deixando um pouco de lado as listas de sequências analíticas de gestos e de atributos tecnotipológicos, descrevendo algumas relações entre pessoas e 'pedras'.

A meu ver, o principal ponto do livro incide nas experiências dos autores, através de projetos de pesquisas que exemplificam seus fundamentos teóricos, seus problemas e as perspectivas abordadas. Contudo, como a proposta do livro refere-se à arqueologia brasileira, a principal crítica diz respeito em não ter explorado, por exemplo, referências sobre estudos de materiais líticos na porção Norte do Brasil, mais especificamente na região amazônica. Talvez esta seja uma lacuna importante a ser apontada, até mesmo devido à escassez de produção bibliográfica sobre o tema.

Como, provavelmente, ainda serão feitos novos congressos sobre tecnologia lítica brasileira, certamente não só a região amazônica entrará em pauta, como também as demais regiões que não foram discutidas neste primeiro livro, formando, assim, um panorama mais amplo, semelhante ao apresentado com maestria pelos organizadores.

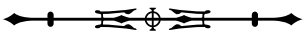

